\title{
Retraction Note to: Static hand gesture recognition using neural networks
}

\author{
Haitham Hasan $^{1}$. S. Abdul-Kareem ${ }^{1}$
}

Published online: 16 February 2017

C) Springer Science+Business Media Dordrecht 2017

\section{Retraction Note to: Artif Intell Rev (2014) 41:147-181 DOI 10.1007/s10462-011-9303-1}

The Editor-in-Chief and the publisher retract the above-mentioned article per the Committee on Publication Ethics (COPE) guidelines on self-plagiarism. The article has significant overlap with two other publications by the same coauthor:

- Haitham Sabah Hasan, Sameem Binti Abdul Kareem, Gesture Feature Extraction for Static Gesture Recognition, Arabian J. for Science and Engineering (2013) 38:12. doi:10. 1007/s13369-013-0654-6

- Haitham Badi, Sabah Hasan Hussein, Sameem Abdul Kareem, Feature Extraction and ML Techniques for Static Gesture Recognition, Neural Computing and Applications (2014) 25:3. doi:10.1007/s00521-013-1540-6

The online version of the original retracted article can be found under doi:10.1007/s10462-011-9303-1.

Haitham Hasan

haitham@siswa.um.edu.my

S. Abdul-Kareem

sameem@um.edu.my.com

1 Faculty of Computer Science and Information of Technology, University of Malaya, 50603 Kuala Lumpur, Malaysia 